\title{
Optimization on Tartary Buckwheat Enriched Steamed Bread: A Response Surface Methodology Study
}

\author{
Xia Wang ${ }^{1}$ and Tianliang Zhang ${ }^{2}$ \\ ${ }^{1}$ School of Public Health, Weifang Medical University, Weifang 261053, China \\ ${ }^{2}$ Medicine Research Center, Weifang Medical University, Weifang 261053, China \\ Correspondence should be addressed to Xia Wang; hawangxia@163.com
}

Received 3 April 2015; Revised 9 June 2015; Accepted 10 June 2015

Academic Editor: Vassiliki Oreopoulou

Copyright (c) $2015 \mathrm{X}$. Wang and T. Zhang. This is an open access article distributed under the Creative Commons Attribution License, which permits unrestricted use, distribution, and reproduction in any medium, provided the original work is properly cited.

Tartary buckwheat, rich in bioactive components such as flavonoids, has been proved beneficial to human health and prevention from many diseases. However, its utilization is limited due to bitterness, roughness, and hardness. The present study was to develop a kind of Tartary buckwheat enriched steamed bread with blends of Tartary buckwheat flour, wheat flour, gluten, glucose oxidase, and pentosanase, using response surface methodology (RSM) to optimize the formula. The independent variables investigated in the present study were the additive amount of gluten, glucose oxidase, and pentosanase, with bread volume and sensory evaluation value as response variables. Based on a basic formula consisting of $250 \mathrm{~g}$ Tartary buckwheat flour, $250 \mathrm{~g}$ wheat flour, $15 \mathrm{~g}$ yeast, and $300 \mathrm{~mL}$ water, the obtained optimum formula was $41.20 \mathrm{~g}$ gluten, $1032 \mathrm{U}$ glucose oxidase, and $56 \mathrm{U}$ pentosanase. Gluten and GOD demonstrated statistically significant effects on Tartary buckwheat steamed bread volume and sensory evaluation values. The validation test results of the optimum formula, with relative error as $0.98 \%$ and $2.55 \%$, were consistent with the theoretically predicted values, demonstrating the reliability of equation and effectiveness of RSM.

\section{Introduction}

Tartary buckwheat (Fagopyrum tataricum) and common buckwheat (Fagopyrum esculentum), belonging to the genus Fagopyrum, are the only two buckwheat species used as food all over the world at present [1]. Both of them are rich in dietary beneficial components, containing relatively high amounts of fibers, vitamins, and proteins with balanced amino acid composition and high significant amounts of bioactive components such as flavonoids [2]. Tartary buckwheat has been drawing more and more attention in recent years due to its benefits for human health. Previous pharmacological investigations demonstrated that Tartary buckwheat had a variety of pharmacological activities of antioxidation [3], antitumor [4], anti-type 2 diabetes [5], total cholesterol reducing [6], and blood lipids regulating [3]. Hence, Tartary buckwheat is recognized as a healthy food. However, its utilization in food processing is limited due to bitterness, roughness, and hardness [7].
Steamed bread, popular in Asian markets and accounting for more than $40 \%$ of national wheat consumption, has been regarded as a stable daily food especially in Northern China [8]. It is considered as healthy food due to the absence of toxic substances generated in other processing methods such as frying and baking. Furthermore, the relatively low processing temperature of steamed bread, not exceeding $100^{\circ} \mathrm{C}$ (if not under pressure), could retain the diverse endogenous and added nutrients to a large extent.

Gluten proteins are technologically vital in many food systems. Wheat-based food processing rearranges the intermolecular disulfide bond cross-links, thereby forming a strong gluten network which greatly determines the structure of bread. During bread making, gluten proteins contribute to dough properties, bread loaf volume and structure, acquiring the desired cooking quality [9].

Glucose oxidase (GOD), a kind of promising green wheat flour strengthening agents, has demonstrated great improvement on rheological and dynamic rheological properties of 
TABLE 1: Basic characteristics of flour used in the study.

\begin{tabular}{lcccccc}
\hline & Moisture content & Protein & Wet gluten & Ash content & Dietary fiber & Total pentosan \\
\hline Wheat flour & $13.20 \%$ & $17.22 \%$ & $39.52 \%$ & $0.49 \%$ & - & $2.18 \%$ \\
$\begin{array}{l}\text { Tartary } \\
\text { buckwheat flour }\end{array}$ & $12.77 \%$ & $11.16 \%$ & - & $0.78 \%$ & $2.11 \%$ & - \\
\hline
\end{tabular}

dough [10-12]. Moreover, GOD is proved to accelerate the oxidative gelation of water-soluble pentosan and strengthen the network structure [13]. Studies showed that pentosanase (PE) exhibited synergistic effect with GOD on the quality of dough. In dough, PE hydrolyzes water-unextractable arabinoxylan (UEAX) into water-extractable arabinoxylan (WEAX) which could form intermolecular cross-links and gel, improving the ductility of dough and quality of bread [14].

RSM is a powerful statistical technique to optimize processes or formula [15]. The optimum ingredient levels can be determined by RSM through variables prediction [16]. Components analysis of Tartary buckwheat found it free from gluten, making it difficult to form the desired shape of final products that customers desired [2]. Hence, the present study aimed to develop a kind of Tartary buckwheat enriched steamed bread optimized by RSM, using gluten, glucose oxidase, and pentosanase as improvers based on a basic formula consisting of $250 \mathrm{~g}$ Tartary buckwheat flour, $250 \mathrm{~g}$ wheat flour, $15 \mathrm{~g}$ yeast, and $300 \mathrm{~mL}$ water.

\section{Materials and Methods}

2.1. Materials. Wheat flour (variety: Jimai 22; origin: Shandong Province, China), free from additive, was purchased from Kiteflour (Co., Ltd., Weifang, China) and Tartary buckwheat flour (variety: Jinqiao 2; origin: Shanxi Province, China) was supplied by Jiaxin Food (Co., Ltd., Datong, China). The flours were manufactured by hammer mill. Glucose oxidase (Gluzyme Mono) containing 10,000 U/g and pentosanase (Pentopan Mono) containing 2,500 U/g were kindly supplied by Novo Nordisk (Shanghai, China). The gluten was provided by Bob's red mill (Co., Ltd., Milwaukie, Oregon, USA). The basic characteristics of flour used in the study were shown in Table 1.

2.2. Instruments. Dough kneading machine and fermentation bin were purchased from Xuzhong Food Machinery (Co., Ltd., Guangzhou, China). Bread volume determinator was supplied by Daji Photoelectric Instrument (Co., Ltd., Hangzhou, China).

2.3. Experimental Design. RSM, involving experimental design, selection of variable levels and appropriate mathematical models by optimizing the response [17], was used in the study. Design-Expert software (Stat-Ease, Minneapolis, USA) was used to design the experiments consisting of three independent variables (Table 2). 15 experiments, involving three factors, namely, gluten, glucose oxidase, and pentosanase, were conducted and these variables were coded as $A, B$, and $C$, respectively. Three experiments at center point (the value
TABLE 2: Experiment design with three factors and three levels.

\begin{tabular}{lcccc}
\hline Factors & Code & -1 & Levels \\
& & 40 & 50 & 60 \\
\hline Gluten/g & $A$ & 500 & 1000 & 1500 \\
GOD/U & $B$ & 30 & 50 & 80 \\
PE/U & $C$ & &
\end{tabular}

of each coded variable was 0 ) were performed to calculate the repeatability of the method [18]. The experiments at center point by the three-variable design were repeated three times, keeping ingredients at levels expected to yield satisfactory experimental results. Steamed bread volume and sensory evaluation value were selected as response variables.

2.4. Manufacture of Steamed Bread. The basic formula consists of $250 \mathrm{~g}$ wheat flour, $250 \mathrm{~g}$ Tartary buckwheat flour, $15 \mathrm{~g}$ yeast, and $300 \mathrm{~mL}$ water. The additive amounts of gluten, glucose oxidase, and pentosanase were shown in Table 2. The materials were blended in dough kneading machine into dough which was incubated in a fermentation bin for $45 \mathrm{~min}$ at $36^{\circ} \mathrm{C}$ at relative humidity of $70 \%$. Then the dough was divided into smaller ones of $80 \mathrm{~g}$ each and kneaded into a round shape using the same intensity and frequency, followed by incubation for another $45 \mathrm{~min}$. Then the breads were steamed for $20 \mathrm{~min}$ and cooled for 1 hour, followed by bread volume measurement and sensory evaluation.

2.5. Sensory Evaluation. Twenty-five assessors (ages ranging from 18 to 30 years, both genders) were recruited from students to taste the steamed bread. Steamed breads of about $10 \mathrm{~g}$ were placed into number coding plastic packs on which the measured specific volumes (volume/weight, $\mathrm{mL} / \mathrm{g}$ ) were marked. Assessors were then asked to assess the attributes: specific volume (volume/weight, $\mathrm{mL} / \mathrm{g}$ ) accounting for $20 \%$, surface texture $5 \%$, appearance and shape features $5 \%$, structure $20 \%$, elasticity $10 \%$, tenacity $10 \%$, viscidity $10 \%$, and odour $20 \%$. The palates were cleansed between samples. Samples were analyzed under normal lighting conditions at room temperature.

2.6. Statistical Analysis. A software package SPSS 19.0 software (IBM, Chicago, IL, USA) was used to determine significant differences among the factors and generate response surface plots. The results were considered statistically significant if the $P$ value was $<0.05$. 
TABLE 3: Design and results of Box-Behnken response surface analysis.

\begin{tabular}{lccccc}
\hline Number & $A$ & $B$ & $C$ & Volume $(\mathrm{mL})$ & $\begin{array}{c}\text { Sensory } \\
\text { evaluation } \\
\text { value (scores) }\end{array}$ \\
\hline 1 & 0 & 1 & -1 & 222.16 & 86.55 \\
2 & 1 & 1 & 0 & 167.24 & 68.32 \\
3 & 0 & 0 & 0 & 243.11 & 90.02 \\
4 & 0 & 0 & 0 & 251.94 & 87.91 \\
5 & -1 & -1 & 0 & 183.46 & 72.30 \\
6 & 1 & 0 & -1 & 166.93 & 58.44 \\
7 & -1 & 0 & -1 & 182.04 & 71.94 \\
8 & -1 & 0 & 1 & 199.35 & 78.02 \\
9 & 0 & 0 & 0 & 243.89 & 83.99 \\
10 & 1 & 0 & 1 & 170.08 & 73.82 \\
11 & -1 & 1 & 0 & 193.64 & 77.63 \\
12 & 0 & -1 & -1 & 187.41 & 77.95 \\
13 & 0 & -1 & 1 & 193.26 & 76.34 \\
14 & 1 & -1 & 0 & 156.88 & 50.53 \\
15 & 0 & 1 & 1 & 252.41 & 87.03 \\
\hline
\end{tabular}

\section{Results and Discussions}

In terms of the Box-Behnken experimental design principle, three independent variables (gluten, glucose oxidase, and pentosanase) which exerted great effects on the quality of steamed bread were investigated by three-factor and threelevel RSM analysis (Table 2). Steamed bread volume and sensory evaluation value served as response variables. The results were shown in Table 3.

3.1. Volume of Tartary Buckwheat Steamed Bread. RSM analyses of Tartary buckwheat steamed bread volumes were conducted by Design-Expert software. The hypothesis testing of the regression equation was performed (Table 4 ). The modeling showed being quite suitable for the prediction of the steamed bread volume, with $P$ value $<0.01, P$ value of lack of fit $>0.05$, and $R^{2}$ value of 0.9500 . The coded variables of both $A$ and $B$ exerted statistically significant effects on the steamed bread volumes, with $P$ values smaller than 0.05 . The regression equation was as follows: $Y=246.33-12.00 A+$ $14.25 B+7.00 C-3.50 A C+6.00 B C-52.67 A^{2}-18.67 B^{2}-$ $14.17 C^{2}$. The absolute values of partial regression coefficient of one degree term were $B>A>C$ within the range of experimental design, demonstrating the greatest effects of GOD on steamed bread volume followed by gluten and PE, respectively.

\subsection{Sensory Evaluation Values of Tartary Buckwheat Steamed} Bread. RSM analyses of sensory evaluation values of Tartary buckwheat steamed bread were conducted by Design-Expert software (Table 5). The modeling was shown quite suitable for the prediction of sensory evaluation values of Tartary buckwheat steamed bread, with $P$ value $<0.05, P$ value of lack of fit $>0.05$, and $R^{2}$ value of 0.9430 . The coded variables of both $A$ and $B$ exerted statistically significant effects on the sensory evaluation values of Tartary buckwheat steamed bread, with $P$ values smaller than 0.05 . The regression equation was as follows: $Y=87.33-6.25 A+5.25 B+2.50 C+3.25 A B+$ $2.25 A C+0.75 B C-16.04 A^{2}-4.54 B^{2}-1.04 C^{2}$. The absolute values of partial regression coefficient of one degree term were $A>B>C$ within the range of experimental design, indicating the greatest effects of gluten on sensory evaluation values of Tartary buckwheat steamed bread followed by GOD and $\mathrm{PE}$, respectively.

In the interactions among gluten, GOD and PE were analyzed to investigate their effects on volumes and sensory evaluation values of Tartary buckwheat steamed bread. The effects on the response variables were intuitively demonstrated in Figures 1 and 2 which revealed that GOD exhibited the greatest effects on the steamed bread volumes followed by gluten, corresponding to a steep curve. However, gluten demonstrated significant effects on the sensory evaluation values of Tartary buckwheat steamed bread followed by GOD, consistent with the results of variance analysis in Tables 4 and 5. On the other hand, no significant change of the two response variables was found with $\mathrm{PE}$ addition, presenting a flat curve.

Tartary buckwheat is rich in proteins but free from gluten. The majority of its protein components were watersoluble albumin and salt-soluble globulin, accounting for more than $80 \%$ of the total proteins [19-21]. Gluten is a kind of highly hydrated protein complexes. When flour is mixed with water to make dough, the water will be absorbed by starch and proteins. Then spatial structure changes of gliadin and glutenin molecular chains will take place, generating stable disulfide bonds through inter- or intramolecular interactions of disulfide, ionic or hydrogen bonds [22]. The intensity and mesh density of the gluten network structure were determined by the number and binding sites of sulfydryl, which directly affected the texture, viscoelasticity, and hardness of flour products $[10,23]$. The formation of suitable gluten structures is prevented after the large amount addition of Tartary buckwheat flour into wheat flour (weight ratio as $1: 1$ ), generating dough with poor extensibility, more crack, and extremely low fermentative capability. The addition of gluten directly increased its proportion in composite flour and improved the air holding capacity of steamed bread, resulting in larger volume after fermentation, homogeneous honeycomb mesh internally, decreased hardness of steamed bread, enhanced specific volume and flexibility, and enlarged sensory evaluation values. It was found appropriate when the added gluten accounted for approximately $10 \%$ of total flour by weight and excessive gluten could lead to difficult dough kneading, smaller volume of steamed bread, and too large toughness.

Regarding the oxidation mechanism of GOD on dough, it is accepted by most scholars that GOD oxidizes D-glucose in the presence of oxygen into $\mathrm{H}_{2} \mathrm{O}_{2}$ which can oxidize the sulfydryl into disulfide bond, leading to enhanced intensity of dough $[11,12,24]$. The oxidation occurred between inter- or intrasubunits of glutenin, which could generate well-organized fibrous macromolecular polymers through 
TABLE 4: Variance analysis on quadratic response surface model of steamed bread volume.

\begin{tabular}{lccccc}
\hline Source of variance & $\begin{array}{c}\text { Quadratic } \\
\text { sum }\end{array}$ & $\begin{array}{c}\text { Degree of } \\
\text { freedom }\end{array}$ & Variance & $F$ value & $P$ value \\
\hline Model & 14703.77 & 9 & 1633.752 & 10.56533 & 0.0092 \\
$A$-gluten & 1152 & 1 & 1152 & 7.449881 & 0.0413 \\
$B$-GOD & 1624.5 & 1 & 1624.5 & 10.5055 & 0.0229 \\
$C$-PE & 392 & 1 & 392 & 2.535029 & 0.1722 \\
$A B$ & 0 & 1 & 0 & 0 & 1.0000 \\
$A C$ & 49 & 1 & 49 & 0.316879 & 0.5978 \\
$B C$ & 144 & 1 & 10241.64 & 66.23178 & 0.3789 \\
$A^{2}$ & 10241.64 & 1 & 1286.564 & 8.320096 & 0.0344 \\
$B^{2}$ & 1286.564 & 1 & 741.0256 & 4.792147 & 0.0802 \\
$C^{2}$ & 741.0256 & 1 & 154.6333 & & $*$ \\
Residual error & 773.1667 & 5 & 241.5 & 9.924658 & 0.0929 \\
Lack of fit & 724.5 & 3 & 24.33333 & & \\
Error & 48.66667 & 2 & & & \\
Sum of deviation & 3481.86 & $R^{2}=0.9500 ;$ adjusted $R^{2}=0.8601$ & & \\
\end{tabular}

${ }^{*, * *}$ There was statistically significant difference between groups.

TABLE 5: Variance analysis on quadratic response surface model of steamed bread sensory evaluation value.

\begin{tabular}{|c|c|c|c|c|c|c|}
\hline Source of variance & Quadratic sum & $\begin{array}{l}\text { Degree of } \\
\text { freedom }\end{array}$ & Variance & $F$ value & $P$ value & \\
\hline Model & 1639.233 & 9 & 182.137 & 9.18338 & 0.0125 & $*$ \\
\hline$A$-gluten & 312.5 & 1 & 312.5 & 15.7563 & 0.0106 & $*$ \\
\hline$B-G O D$ & 220.5 & 1 & 220.5 & 11.11765 & 0.0207 & $*$ \\
\hline C-PE & 50 & 1 & 50 & 2.521008 & 0.1732 & \\
\hline$A B$ & 42.25 & 1 & 42.25 & 2.130252 & 0.2042 & \\
\hline$A C$ & 20.25 & 1 & 20.25 & 1.021008 & 0.3587 & \\
\hline$B C$ & 2.25 & 1 & 2.25 & 0.113445 & 0.7499 & \\
\hline$A^{2}$ & 950.1603 & 1 & 950.1603 & 47.90724 & 0.0010 & $* *$ \\
\hline$B^{2}$ & 76.16026 & 1 & 76.16026 & 3.840013 & 0.1073 & $*$ \\
\hline$C^{2}$ & 4.00641 & 1 & 4.00641 & 0.202004 & 0.6719 & \\
\hline Residual error & 99.16667 & 5 & 19.83333 & & & \\
\hline Lack of fit & 80.5 & 3 & 26.83333 & 2.875 & 0.2686 & \\
\hline Error & 18.66667 & 2 & 9.333333 & & & \\
\hline Sum of deviation & 1738.4 & 14 & & & & \\
\hline \multicolumn{7}{|c|}{$R^{2}=0.9430 ;$ adjusted $R^{2}=0.8403$} \\
\hline
\end{tabular}

${ }^{*, * *}$ There was statistically significant difference between groups.

intermolecular disulfide bond, improving the structure of gluten besides air holding capacity and ductility of dough. The results revealed that the addition of GOD resulted in increased volumes and sensory evaluation values, enhanced specific volume, flexibility and toughness, and decreased hardness of the Tartary buckwheat steamed bread, consistent with the study of Steffolani et al. [11].

Similar to gluten, excessive addition of GOD could give rise to excessively oxidized dough and destructed gluten [10, 12], characterized by decreased volumes, internal inhomogeneous holes, and increased hardness of Tartary buckwheat steamed bread. The optimum additive amount of GOD, much higher than that in wheat flour, was $2064 \mathrm{U}$ per kilogram composite flour, which may be related to the protein content and proportion in bitter buckwheat flour [10]. Junko et al. investigated the protein components in Tartary buckwheat and found that the proportions of albumin, globulin, gliadin, and gluten were $30-35 \%, 45-50 \%, 1-1.5 \%$, and $15-20 \%$, small molecular proteins of the first two accounting for more than $80 \%$ of total proteins. And the cysteine content in Tartary buckwheat, $5 \%$ of total weight, is higher than that in wheat flour $[19,20]$, leading to increased substrate of GOD, declined 


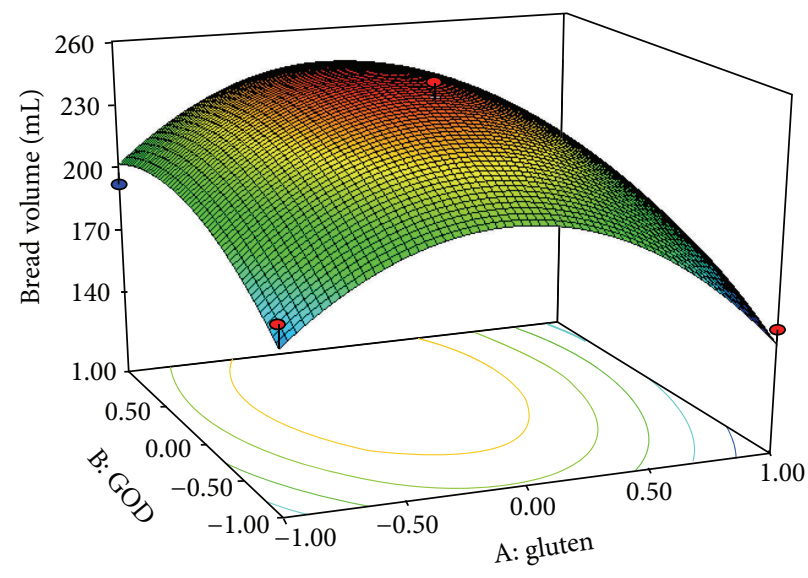

(a)

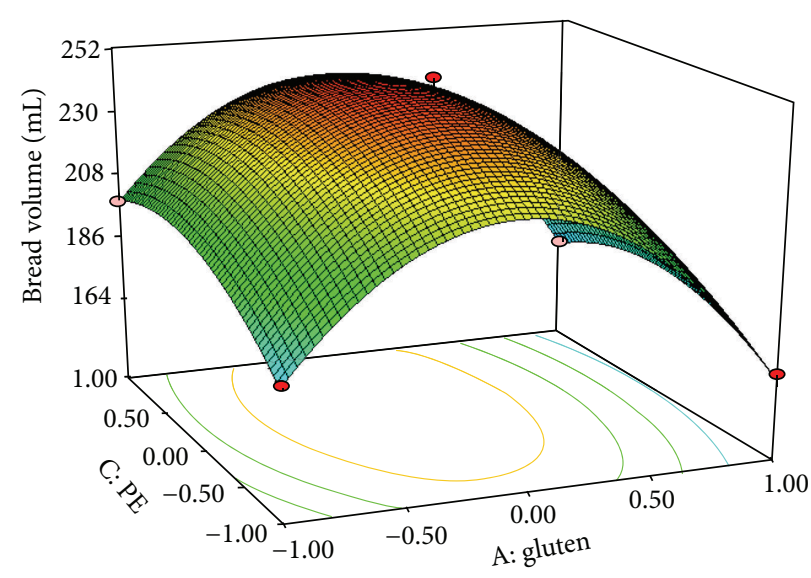

(b)

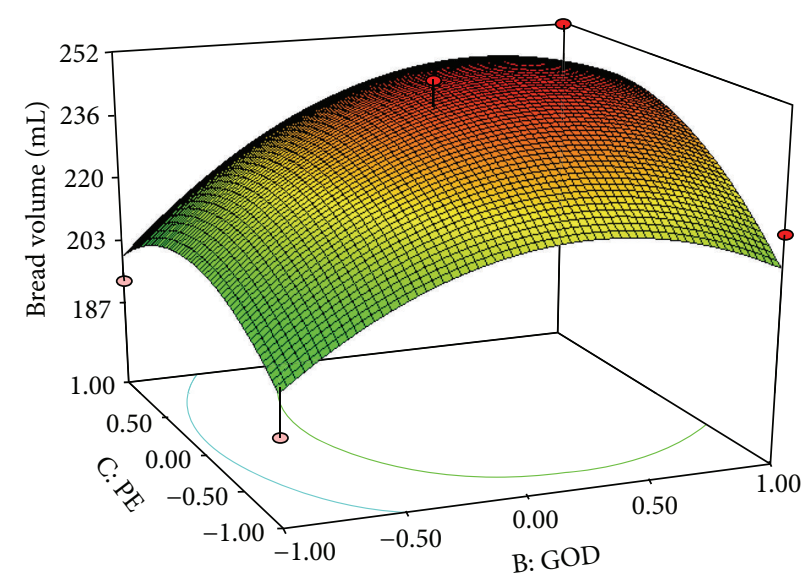

(c)

FIGURE 1: Effects of interactions among gluten, GOD, and PE on the volume of steamed bread.

oxidation ability, and increased addition of GOD eventually $[10,24]$.

$\mathrm{PE}$, another flour improver widely accepted by domestic and overseas scholars, mainly hydrolyzes insoluble pentosan and plays roles in machinability enhancement, excessive fermentation elimination, volume and quality of flour products increase, and aging delaying [11]. Tartary buckwheat is rich in insoluble pentosan [19]. Though the addition of PE did not show significant effects on the volumes and sensory evaluation values, it could improve the elasticity of bread, the mechanism of which needs further intensive investigation.

Rosell et al. found that the changes promoted by glucose oxidase treatment exhibited very pronounced effects on the physical properties of wheat flour but did not introduce changes in the protein profiles [25]. In consideration of its substrate not as protein but as arabinoxylan, the addition of pentosanase should not cause changes of protein content or variety theoretically, which needs verification by experiment indeed. Therefore, the auxiliary materials used in the present study could be promising improvers for Tartary buckwheat enriched steamed bread without changing the overall nutrition.
3.3. Formula Optimization. Based on the Design-Expert software, the maximum points of regression equation were gluten of $41.20 \mathrm{~g}$, GOD of $1032 \mathrm{U}$, and PE of $56 \mathrm{U}$, with predicted Tartary buckwheat steamed bread volume as $258.93 \mathrm{~mL}$ and sensory evaluation value as 94.52 . Three paralleled experiments according to these process parameters were performed and the results generated mean Tartary buckwheat steamed bread volume as $256.41 \mathrm{~mL}$ and sensory evaluation value as 92.17 with relative error as $0.98 \%$ and $2.55 \%$ compared with the theoretically predicted value, respectively, demonstrating the reliability of equation and the effectiveness of RSM.

\section{Conclusion}

The addition of gluten and GOD exerted statistically significant effects on Tartary buckwheat steamed bread volumes and sensory evaluation values. The validation test results of the optimum formula were consistent with the theoretically predicted values, demonstrating the reliability of equation and the effectiveness of RSM.

\section{Conflict of Interests}

The authors declare no conflict of interests. 


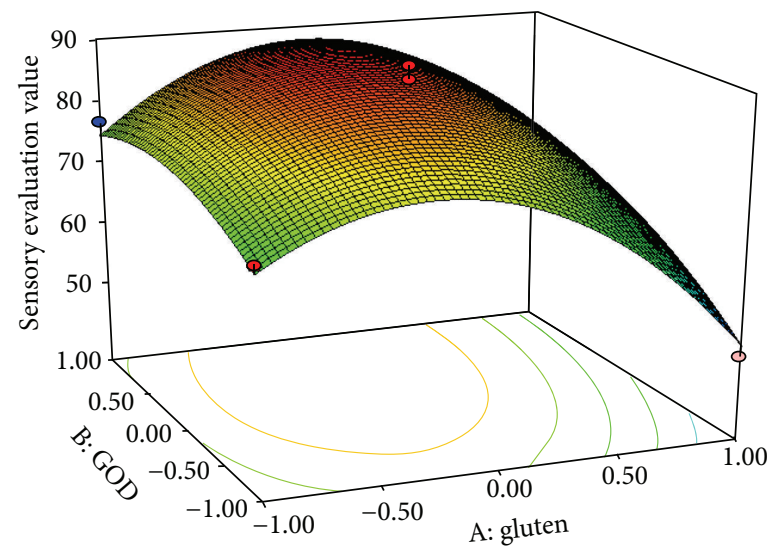

(a)

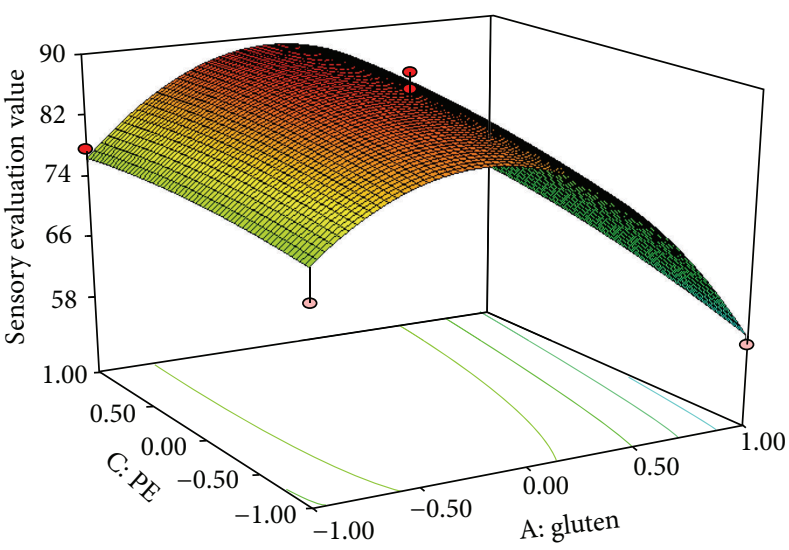

(b)

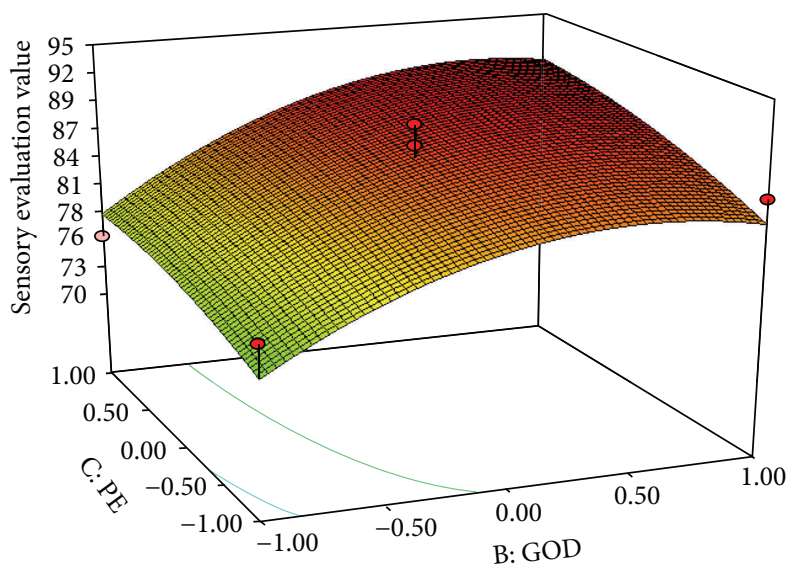

(c)

FIGURE 2: Effects of interactions among gluten, GOD, and PE on the sensory evaluation value of steamed bread.

\section{Acknowledgments}

This work was financially supported by a grant from Natural Science Foundation of Shandong Province (ZR2014CP004) and Youth Innovation Foundation of Weifang Medical University (K11QC1012).

\section{References}

[1] N. Fabjan, J. Rode, I. J. Kosir, Z. Wang, Z. Zhang, and I. Kreft, "Tartary buckwheat (Fagopyrum tataricum Gaertn.) as a source of dietary rutin and quercitrin," Journal of Agricultural and Food Chemistry, vol. 51, no. 22, pp. 6452-6455, 2003.

[2] G. Bonafaccia, M. Marocchini, and I. Kreft, "Composition and technological properties of the flour and bran from common and tartary buckwheat," Food Chemistry, vol. 80, no. 1, pp. 9-15, 2003.

[3] M. Wang, J.-R. Liu, J.-M. Gao, J. W. Parry, and Y.-M. Wei, "Antioxidant activity of tartary buckwheat bran extract and its effect on the lipid profile of hyperlipidemic rats," Journal of Agricultural and Food Chemistry, vol. 57, no. 11, pp. 5106-5112, 2009.

[4] X. Guo, K. Zhu, H. Zhang, and H. Yao, "Purification and characterization of the antitumor protein from Chinese tartary buckwheat (Fagopyrum tataricum Gaertn.) water-soluble extracts," Journal of Agricultural and Food Chemistry, vol. 55, no. 17, pp. 6958-6961, 2007.

[5] Y. Yao, F. Shan, J. Bian, F. Chen, M. Wang, and G. Ren, “Dchiro-inositol-enriched tartary buckwheat bran extract lowers the blood glucose level in KK-A $\mathrm{A}^{\mathrm{y}}$ mice," Journal of Agricultural and Food Chemistry, vol. 56, no. 21, pp. 10027-10031, 2008.

[6] H. Tomotake, N. Yamamoto, N. Yanaka et al., "High protein buckwheat flour suppresses hypercholesterolemia in rats and gallstone formation in mice by hypercholesterolemic diet and body fat in rats because of its low protein digestibility;" Nutrition, vol. 22, no. 2, pp. 166-173, 2006.

[7] Y. J. Ma, X. D. Guo, H. Liu, B. N. Xu, and M. Wang, "Cooking, textural, sensorial, and antioxidant properties of common and tartary buckwheat noodles," Food Science and Biotechnology, vol. 22, no. 1, pp. 153-159, 2013.

[8] Z. H. He, A. H. Liu, R. J. Peña, and S. Rajaram, "Suitability of Chinese wheat cultivars for production of northern style Chinese steamed bread," Euphytica, vol. 131, no. 2, pp. 155-163, 2003.

[9] J. A. Delcour, I. J. Joye, B. Pareyt, E. Wilderjans, K. Brijs, and B. Lagrain, "Wheat gluten functionality as a quality determinant in cereal-based food products," Annual Review of Food Science and Technology, vol. 3, no. 1, pp. 469-492, 2012.

[10] J. C. Pescador-Piedra, R. R. Farrera-Rebollo, and G. CalderónDomínguez, "Effect of glucose oxidase and mixing time on 
soluble and insoluble wheat flour protein fractions: changes on SH Groups and $\mathrm{H}_{2} \mathrm{O}_{2}$ Consumption," Food Science and Biotechnology, vol. 19, no. 6, pp. 1485-1491, 2010.

[11] M. E. Steffolani, P. D. Ribotta, G. T. Pérez, and A. E. León, "Effect of glucose oxidase, transglutaminase, and pentosanase on wheat proteins: relationship with dough properties and bread-making quality," Journal of Cereal Science, vol. 51, no. 3, pp. 366-373, 2010.

[12] M. R. Pirozi, B. Margiotta, D. Lafiandra, and F. MacRitchie, "Composition of polymeric proteins and bread-making quality of wheat lines with allelic HMW-GS differing in number of cysteines," Journal of Cereal Science, vol. 48, no. 1, pp. 117-122, 2008.

[13] M. A. Martínez-Anaya and T. Jiménez, "Rheological properties of enzyme supplemented doughs," Journal of Texture Studies, vol. 28, no. 5, pp. 569-583, 1997.

[14] C. Primo-Martín and M. A. Martínez-Anaya, "Influence of pentosanase and oxidases on water-extractable pentosans during a straight breadmaking process," Journal of Food Science, vol. 68, no. 1, pp. 31-41, 2003.

[15] D. Baş and I. H. Boyaci, "Modeling and optimization I: usability of response surface methodology," Journal of Food Engineering, vol. 78, no. 3, pp. 836-845, 2007.

[16] P. Crowley, H. Grau, P. O’Connor, R. J. FitzGerald, and E. K. Arendt, "Effect of glutamine peptide on baking characteristics of bread using experimental design," European Food Research and Technology, vol. 212, no. 2, pp. 192-197, 2001.

[17] A. I. Khuri, "Response surface models with mixed effects," Journal of Quality Technology, vol. 28, no. 2, pp. 177-186, 1996.

[18] S. Saha and A. I. Khuri, "Comparison of designs for response surface models with random block effects," Quality Technology and Quantitative Management, vol. 6, pp. 219-234, 2009.

[19] K. J. Steadman, M. S. Burgoon, B. A. Lewis, S. E. Edwardson, and R. L. Obendorf, "Buckwheat seed milling fractions: description, macronutrient composition and dietary fibre," Journal of Cereal Science, vol. 33, no. 3, pp. 271-278, 2001.

[20] D. Junko, C. Hiroko, and C. Takanorl, "Study on the globulin of tartay buckwheat," Journal of Japanese Society of Nutrition and Food Science, vol. 48, pp. 61-65, 1995.

[21] L. Han, Y. Zhou, E. Tatsumi, Q. Shen, Y. Cheng, and L. Li, "Thermomechanical properties of dough and quality of noodles made from wheat flour supplemented with different grades of tartary buckwheat (Fagopyrum tataricum gaertn.) flour," Food and Bioprocess Technology, vol. 6, no. 8, pp. 1953-1962, 2013.

[22] I. Rombouts, B. Lagrain, K. Brijs, and J. A. Delcour, "Crosslinking of wheat gluten proteins during production of hard pretzels," Amino Acids, vol. 42, no. 6, pp. 2429-2438, 2012.

[23] B. Lagrain, E. Wilderjans, C. Glorieux, and J. A. Delcour, "Importance of gluten and starch for structural and textural properties of crumb from fresh and stored bread," Food Biophysics, vol. 7, no. 2, pp. 173-181, 2012.

[24] C. Don, G. Mann, F. Bekes, and R. J. Hamer, "HMW-GS affect the properties of glutenin particles in GMP and thus flour quality," Journal of Cereal Science, vol. 44, no. 2, pp. 127-136, 2006.

[25] C. M. Rosell, J. Wang, S. Aja, S. Bean, and G. Lookhart, "Wheat flour proteins as affected by transglutaminase and glucose oxidase," Cereal Chemistry, vol. 80, no. 1, pp. 52-55, 2003. 

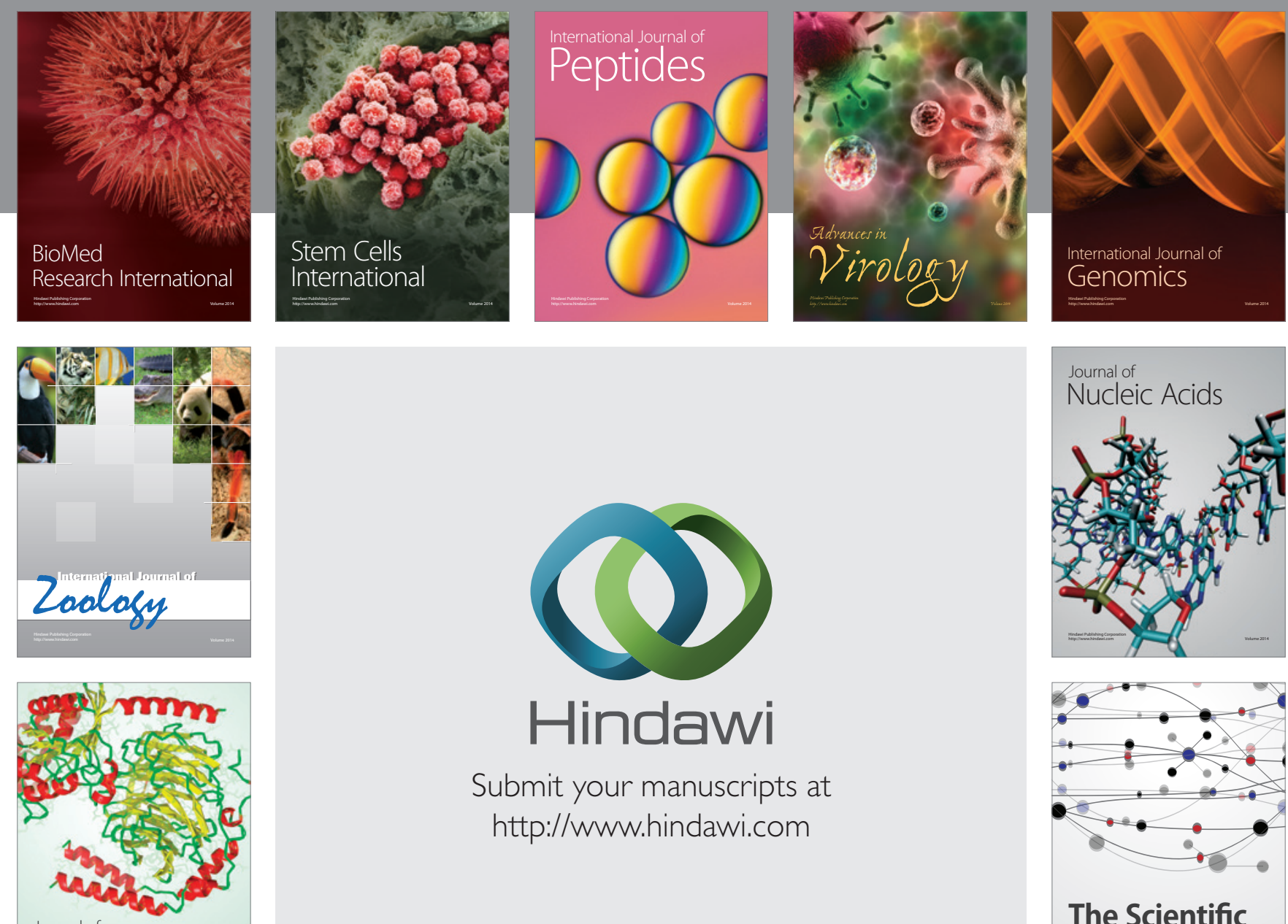

Submit your manuscripts at

http://www.hindawi.com

Journal of
Signal Transduction
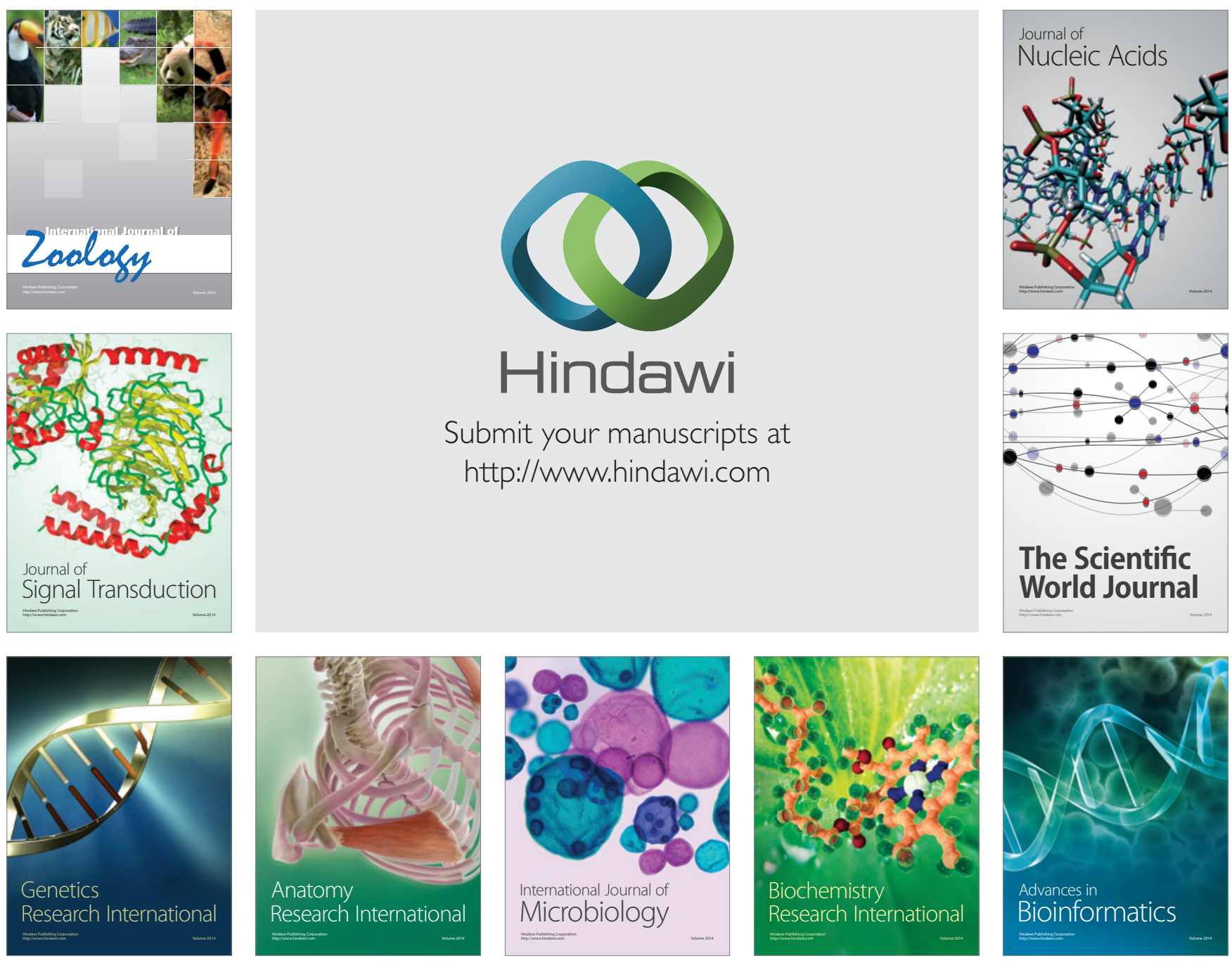

The Scientific World Journal
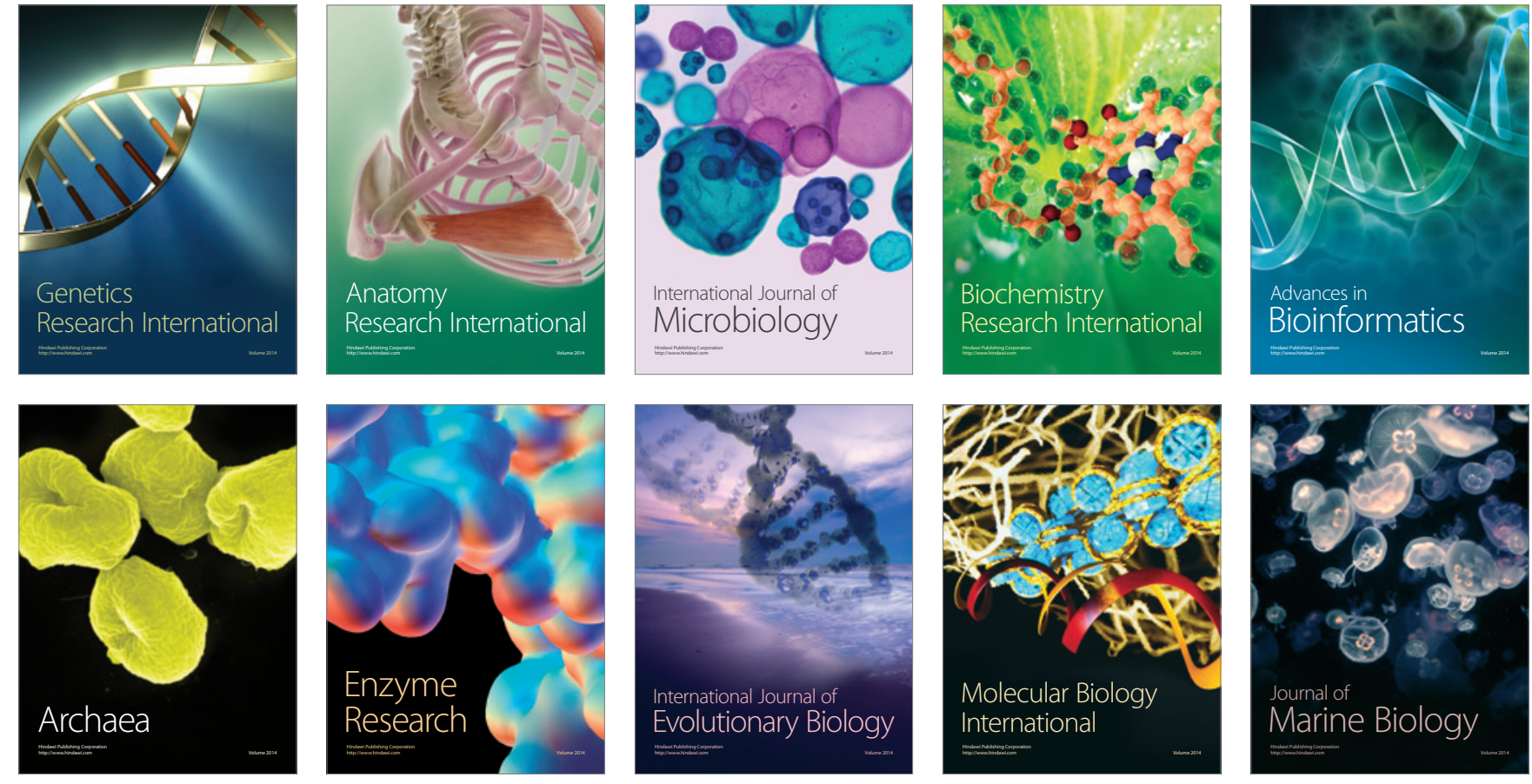